\title{
MULTI-CRITERIA ASSESSMENT AND PROCESS SELECTION MODEL FOR ADDITIVE MANUFACTURING IN THE CONCEPTUAL PHASE OF DESIGN
}

\author{
Tavcar, Joze; \\ Nordin, Axel \\ Lund University
}

\begin{abstract}
Additive manufacturing (AM), which was first applied for rapid prototyping, is now becoming a real option for small-batch production of final products. Further expansion of AM is closely correlated to production costs. AM can only become competitive to traditional manufacturing methods if a product is designed for AM already from the beginning as it is an expensive technology that should only be applied if it adds enough value to the product. The aim of this paper is to increase cost awareness in the conceptual design phase and to support product developers in doing AM cost estimation and process selection. The proposed model integrates design for AM and costs calculation. The input data to the process is preliminary design and design requirements. The main contribution of this paper is the multi-criteria AM function, which enables concurrent consideration of different technical and economical criteria. The multi-criteria AM function helps to compare how AM processing and product design parameters influence the product cost. The holistic overview of different options increases the solution space and enables product optimization in several iterations.
\end{abstract}

Keywords: Design costing, Design for Additive Manufacturing (DfAM), Conceptual design, Concurrent Engineering (CE), process selection

\section{Contact:}

Tavcar, Joze

Lund University

LTH, Design Science, Product development

Sweden

joze.tavcar@design.lth.se

Cite this article: Tavcar, J., Nordin, A. (2021) 'Multi-Criteria Assessment and Process Selection Model for Additive Manufacturing in the Conceptual Phase of Design', in Proceedings of the International Conference on Engineering Design (ICED21), Gothenburg, Sweden, 16-20 August 2021. DOI:10.1017/pds.2021.481 


\section{INTRODUCTION}

Further expansion of additive manufacturing (AM) from prototyping to production of final products in small batch quantities is closely correlated to production costs. Competences of product developers and competitive production costs are key drivers that will expand the use of AM. Application of AM can be competitive to traditional manufacturing methods only if the product is designed for AM already from the beginning. The aim of this paper is to increase cost awareness in the conceptual design phase and support product developers at AM cost estimation. It cannot be emphasized enough the importance of the early life phases for the product's success. Any mistakes made here can be corrected later only with great effort (Ehrlenspiel et al., 2007).

Additive manufacturing (AM) was applied first for rapid prototyping (RP). Prototypes are typically produced in low quantities and costs are not the most critical parameter. The added value of RP is early feedback information to product developers and for communication with customers. The product must be designed and optimized for the manufacturing process that will be applied in a serial production and not for prototyping. However, AM is increasingly used as a production technology and the industry must change the perception that AM is cost efficient only for RP. Demonstrating a real added value for production with 3D printing at scale will increase the use of 3D printing for production (Sculpteo, 2015).

In this paper, a model for a computer aided tool was developed that aids the cost awareness of the product designer. As AM is not the best option for each product, the product design must be evaluated first according to different criteria. If the product does not contain specific design features that can be manufactured only with AM then applicability of other manufacturing processes must be explored. Moreover, product design can significantly influence the AM processing cost. The product designer must ensure that the advantages and limitation of AM processing were considered. Product re-design must be conducted if design for AM was not already applied.

In the second step, a selection of a proper AM technology is done according to the product design requests such as mechanical properties, tolerances, temperature resistance, maximum size, etc. As the choice of AM technology has significant influence on product cost, it is important that the product only meets the most crucial requirements.

In the last step, a case study of cost assessment is conducted based on a defined part geometry and AM processing technology. The presented approach will be implemented as a Web-based application. New technologies and materials are being developed and their costs are reducing; therefore, it is necessary to regularly update information. A special multi-criteria function is introduced that helps to consider several criteria concurrently. The key idea of the presented tool is to support the product developer and increase AM cost awareness in the product conceptual design phase.

\section{LITERATURE REVIEW}

AM is a relatively expensive and slow technology that should only be used for production if it adds enough value to the product, logistics, and time to market beyond that which could be added with conventional manufacturing (Diegel et al. 2020). A production component that was designed for 3axis CNC machining, for example, will generally be more expensive to manufacture with AM. There is general agreement that, for AM to offer maximum value, the parts must be designed for AM (DfAM) (Diegel et al. 2020). The typical hourly operation costs of a metal AM machine can range from about $€ 37 / \mathrm{h}$ to $€ 90 / \mathrm{h}$ (depending on the cost of the machine). On top of the direct machine costs, with metal AM there are often substantial post-processing costs (Inex-adAM, 2019). This cost includes the time it takes heat-treat the part, remove the part from the build platform, remove all the support material from the part, and then give it an acceptable surface finish (Diegel et al. 2020). Some companies, including Daimler, Premium Aerotec, EOS and Materialise estimate that as much as 70\% of part cost can be spent on pre- and post-processing. Electron Beam Melting (EBM) and Direct Metal Laser Sintering (DMLS) was compared on cost performance by Baumers. High specific costs $(€ 2.66$ and $€ 6.87$ per $\mathrm{cm}^{3}$ of material) and limited deposition rate are identified as central obstacles to more widespread use (Baumers, 2017).

The technical planning departments (product development and production planning) set approximately 90\% of the product costs. There is an enormous difference between the product development department's crucial responsibility for product costs, and their own costs, which amount to approximately one-eighth of the total (Ehrlenspiel et al., 2007). Systematically reworking the part design 
reduced the manufacturing costs in average by 33\% (Ehrlenspiel et al., 2007), by applying design for AM cost saving can even higher (Diegel et al, 2020). The cost-conscious product developers should not allow the function of a product or part to totally guide their work. The developers should also think ahead to the manufacturing processes (Ehrlenspiel et al., 2007). Cost reduction shall consider material costs, production labour, and overhead costs, R\&D costs, administration costs, and sales. Manufacturing cost reduction include material costs, part production and assembly costs (Ehrlenspiel et al., 2007).

\subsection{Support systems for RP process selection}

Byun and Lee (2005) identified six attributes for the selection and evaluation of rapid prototyping (RP) process, namely accuracy, surface roughness, tensile strength, elongation, cost of the part and build time. The build time includes the pre-processing time, building time and post-processing time. The part cost includes both material and labour costs. Armillotta (2008) developed the decision criteria, including all relevant and independent requirements of AM techniques for prototyping and tooling processes. Eleven attributes were presented, concerning part properties, production features, and operation costs.

\subsection{Machine and material costs}

Kampker et al. provide a technological and economic comparison of 10 different AM materials with respect to their potential for the use of injection tool production, thus serving as an orientation for tool material selection for design engineers. PerFrom and PA 3200 GF offer the highest technological potential even for high melting polymer materials (Kampker, 2018). Material costs constitute a major proportion of the cost of a product produced using AM. The AM system is also a significant cost factor; however, this cost has continually decreased by $51 \%$ per decade (Douglas, 2016). Economic Analysis of AM machines has shown that higher profits are achieved with machines with higher productivity, although the purchase prices are higher. The fused deposition model (FDM) technology printers are less suitable solution for production, due to its inability to build multiple objects at the same time - low productivity (Tagliaferri, 2019).

\subsection{Part quantities and break-even point}

Hopkinson et al. (2006) estimate for their sample part that AM is cost-effective for volumes of up to between 6000 and 14000 , depending on the AM system. Sculpteo determined the relative cost of the initial setup and the overall cost of the batch size. The study identified a break-even point between 300 and 400 units depending on complexity and part size (Sculpteo, 2015).

Atzeni and Salmi (2012) examined the production of a metal landing gear assembly and estimated that AM is cost-effective for production runs of up to 42 products. AM not only cannot compete with conventional manufacturing for mass production, but also is not suitable for larger batch production system, which is more than 200 parts in the case presented by Niaki (Niaki et al., 2019). In general $\mathrm{AM}$ can be a suitable alternative to conventional manufacturing for low-volume production, i.e. less than 40 parts. However, it depends on the capacity of machine, material properties and required quality levels (Niaki et al., 2019).

The literature review shows several trials on AM cost analysis estimation. Some of the presented concepts and approaches can be reused as a guideline. However, information on material and processing costs are changing all the time, therefore it is difficult for a design engineer to reliably estimate costs for different AM processes. There are on-line calculators that can be helpful, but they require time and a well specified product (with 3D model). All AM machines have a good preprocessing software that can precisely estimate material costs and processing time. But, the preliminary decisions on product design and AM processing must be taken before, already in the conceptual phase of design. The paper contribution is a model for AM processing cost estimation and AM process selection, which is supposed to be use in the conceptual phase of product design. A novel is the multi-criteria $\mathrm{AM}$ function (MCF) that enables flexible comparison between different $\mathrm{AM}$ technologies and iterative product design.

\section{METHODS}

AM process selection and cost estimation must be first positioned into product development process. The concurrent engineering approach (Stjepandic, 2015) assume concurrent product design and 
process planning. A cost-efficient product must be designed for a specific manufacturing process already in the conceptual phase. The interaction between product design and manufacturing process is split into three iteration loops (Fig. 1). Product development starts with a product specification and business model that contains the expected quantities.

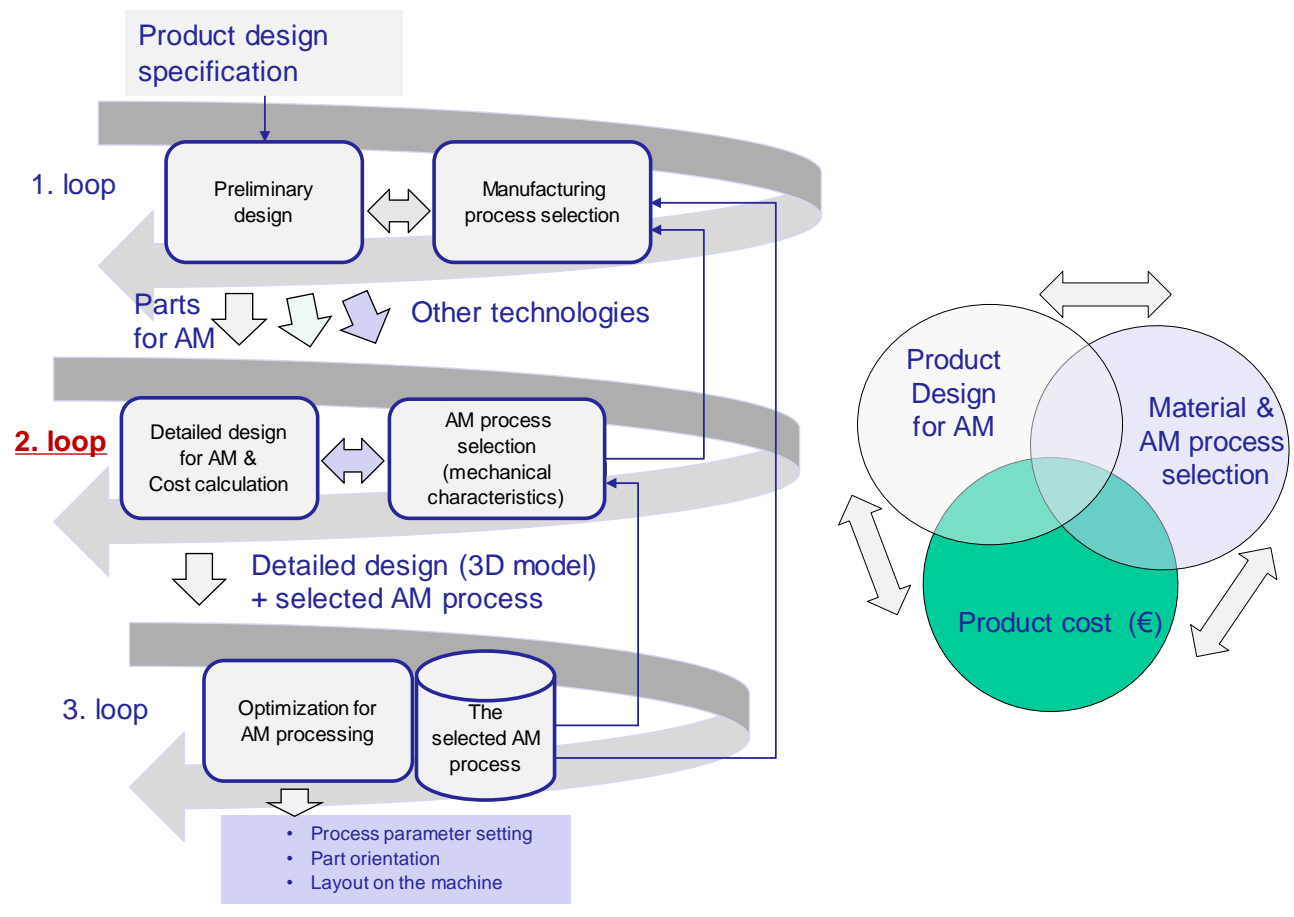

Figure 1: Detailed design for AM and costs calculation is in the second loop of product development process

A preliminary product design is done in the first loop. It is recommended to select the manufacturing process according to the requested technical characteristics, expected quantities, and target costs already in the first loop. The design space must consider all manufacturing technologies, as technical and economical optimization cannot otherwise be properly conducted. According to Ehrlenspiel et al., the early decisions in the product development process significantly impact the costs throughout the product life cycle (Ehrlenspiel et al., 2007).

If AM technology is deemed appropriate, then even the preliminary design must consider specific requirements of the proposed manufacturing technology. The second loop is the focus of this publication (Fig. 1). The proposed model supports the designer at AM cost assessment and AM process selection. After several iterations of the second loop, an optimum is found that consider product design, technical characteristics and AM processing. The method is based on the designers taking an active role throughout the optimization process.

Input into the third loop is a detailed product design (3D model) and a selected AM process. The third loop contains AM process optimization for the specific machine. Proper parameter setting, and layout on the machine can have an important impact on processing time, costs, and technical characteristics. Such optimization is usually done with a special software supplied together with AM machine. The third loop is out of scope of this publication.

The supporting tool presented in this paper was developed on the base of identified needs of product development process, design for AM, AM technologies, and results of other researchers. Increasing cost awareness and opening the design space already in the conceptual phase of design is more important than the accuracy of cost calculations. Preliminary cost calculation is enabled already with basic input data. The cost estimation model assumes that the product designer is included in the decision loop. However, the authors propose the multi-criteria AM function that concentrate all criteria and parameters into one number. The multi-criteria AM function helps to keep overview of several criteria and find a balance between technical characteristics and costs (Tavčar et al., 2020). The proposed model integrates product cost calculation, design for AM and selection of AM processing. All the topics are interconnected between each other and therefore must be considered concurrently. 


\section{RESULTS}

\subsection{Integrated design for $\mathrm{AM}$ and cost calculation model}

Proper design for AM has a significant influence on costs (Diegel et al., 2020). Calculating costs, without first verifying if the product design considers the basic rules for AM, would result to large scatter at cost assessment. AM technology open new possibilities for integrating several parts together and reducing assembly costs. Radically new design solutions can significantly reduce material and processing costs. Therefore, the proposed model integrates design for AM and costs calculation. The integrated process is presented in Fig. 2. The input data to the process is preliminary design and design requests. The decision to manufacture the product with AM has been taken already in the first loop (Fig. 1). In the second loop, the design engineer is detailing the product in several iterations. Design iterations are based on awareness of how different AM technologies determine technical characteristics and costs. This holistic view increases space for solutions and enables finding cost efficient design. Small modifications in design can reduce requests for tolerances, and in this way enable application of more affordable AM technology.

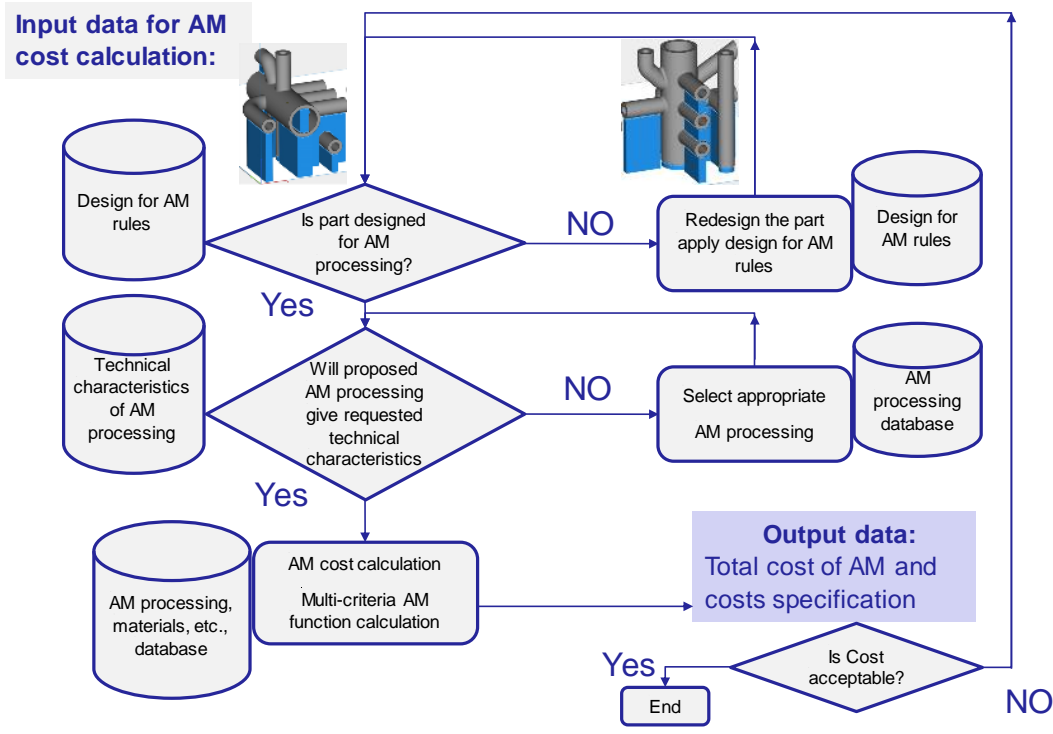

Figure 2: Integrated process of design for $A M$ and cost calculation

\subsection{Design for AM}

The purpose of this publication is not to give a comprehensive review of guidelines for proper design for AM. Figure 3 summarize some of the general design rules for AM.

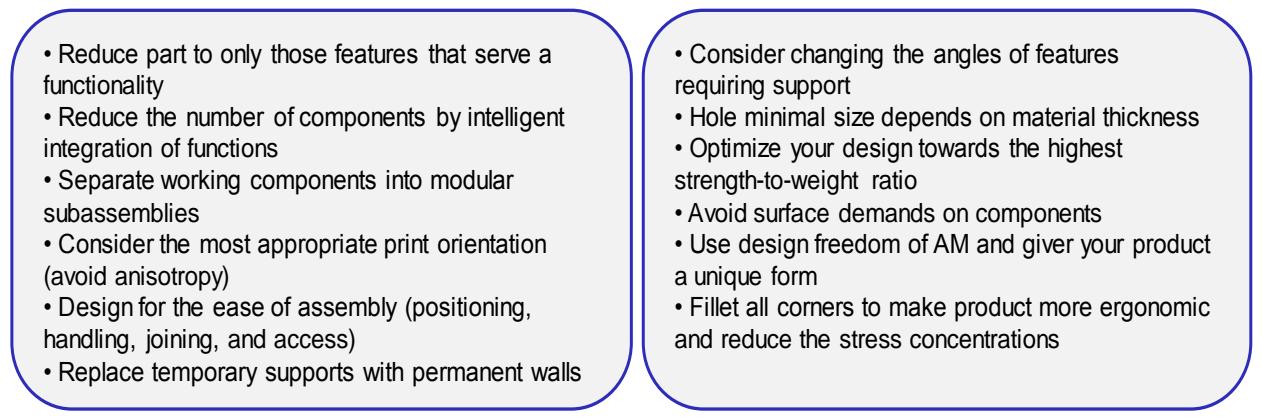

Figure 3: General design rules for AM, Diegel et al., (2020), Becker et al. (2005)

When the product design for AM is determined and appropriate AM technology is selected, costs calculation starts (Fig. 2 There are two options for cost calculation as presented in Fig. 4. If the material and AM process are defined, the user can enter data for product volume and pre- and postprocessing cost (Fig. 4, B1). The computer program estimates costs for material, AM processing, pre- 
and post-processing. In loop 2, a cost approximation and processing time is needed for comparison between different design and processing options. If the product material and AM process are not yet defined, then the user inputs the requested mechanical characteristics, material temperature range and product quality range (Fig. 4, B2). The output of the computer program is cost structure for all AM processes (machines) that fulfil the requested technical characteristics (Fig. 4). The multi-criteria AM function, that will be presented in the next section, was specified for easier and more structured comparison between different design and AM processing options.

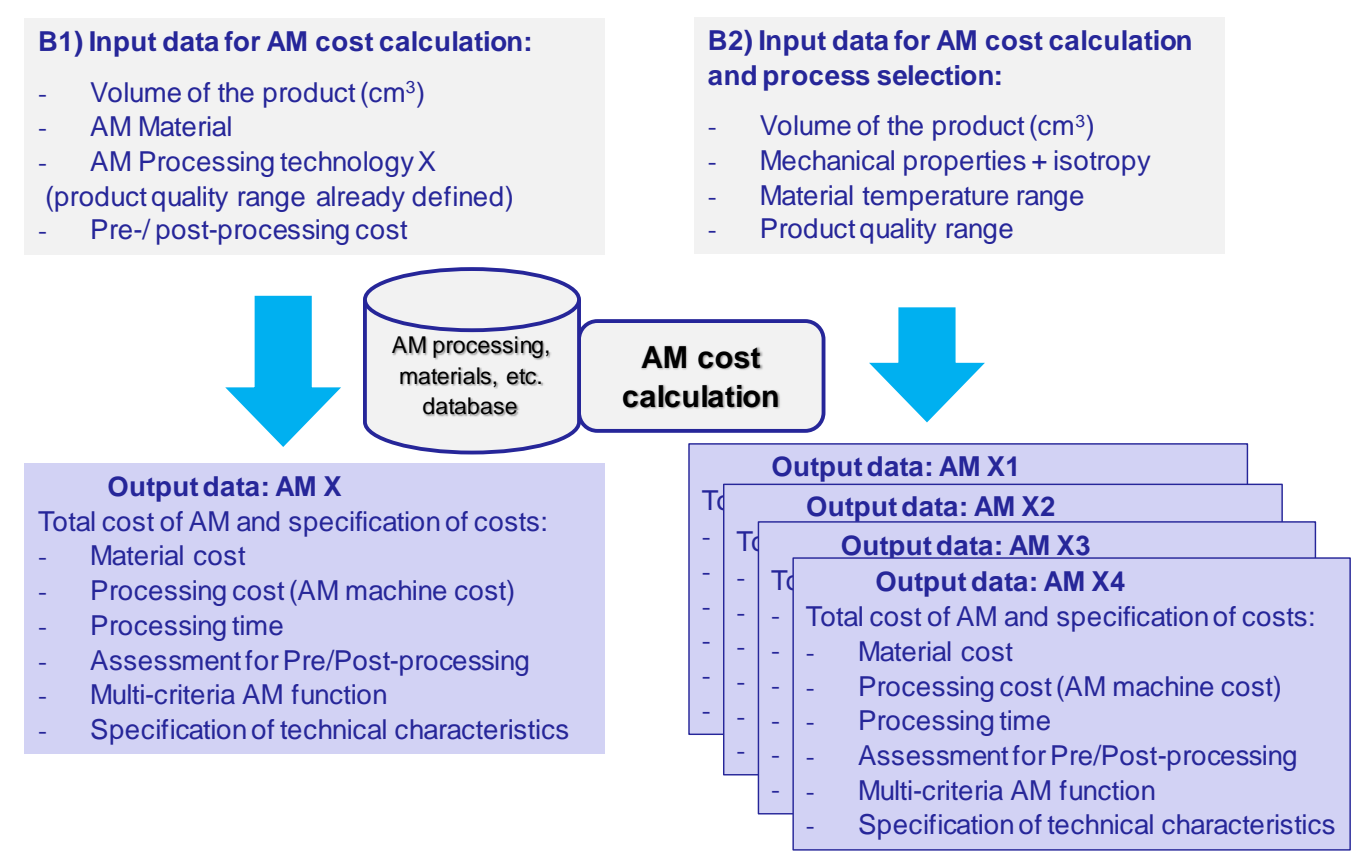

Figure 4: Cost calculation model (B1) and AM process selection (B2)

\subsection{Multi-criteria AM function}

Each product design requires specific technical characteristics, which are determined by selection of the material and AM processing technology. Presenting and assessing those technical characteristics together with economic parameters poses a challenge. If the product design is fixed, we can only select optimal material and AM processing (that fulfil technical characteristics and have minimal cost).

The multi-criteria AM function (MCF) (Eq. (1)) is the result of our research. With introduction of the multi-criteria function, the product designer gets information on sensitivity of the product on cost and technical characteristics. For example: by re-designing the product, the requested strength or quality can be reduced. It enables applying of more affordable AM processing. It is also possible to see that a specific processing technology enables high material strength that is not utilized in the current product design. Concurrent modifications of product design and AM processing enables cost optimization.

The multi-criteria function (Eq. (1)) consists of one value or element $\left(M C F_{i}\right)$ for each criterion. Each criterion in an application is compared with a limit value for the selected material. In this way, different criteria can be compared between each other. If the value of the criterion such as $T_{b u l k}$ is larger than the maximum allowed temperature for the selected material $\left(T_{\max }\right)$ the value of $\left(T_{\text {bulk }} / T_{\max }=M C F_{i}\right)$ will be greater than 1 . The square function will additionally increase the value of multi-criteria function and emphasize that the criterion is not fulfilled. Each criterion that is not fulfilled will significantly increase MCF. If the value $M C F_{i}$ is smaller than 1 the square root function is applied. In this way MCF reduces impact of criteria that significantly fulfil requirements (Eq. (1)). The MCF help to find a trade-off between technical and economic criteria in a common equation. Each of the criteria can have additional weight $\left(w_{x}\right)$ that enables the product designer additionally increase importance of particular criterion.

Half of the values in MCF is determined with the selected material and AM processing (marked with bold in Eq. (1), and the other half with product design and application demands. The MCF helps to find balance between all criteria and constraints. 


$$
\begin{aligned}
M C F= & \sum_{i=0}^{n}\left(w_{\mathrm{i}} \cdot\left(M C F_{\mathrm{i}}\right)^{\mathrm{c}}\right)=w_{\mathrm{T}} \cdot\left(\frac{T_{\mathrm{bulk}}}{\boldsymbol{T}_{\max }}\right)^{c}+w_{\sigma} \cdot\left(\frac{\sigma_{\mathrm{p}}}{\sigma_{\max }}\right)^{c}+w_{\text {Iso }} \cdot\left(\frac{\text { Iso } \min }{\boldsymbol{I s o}_{\mathrm{AM}}}\right)^{c}+w_{\mathrm{Q}} \cdot\left(\frac{\boldsymbol{Q}_{\mathrm{AM}}}{Q_{P}}\right)^{c}+ \\
& w_{\mathrm{C}} \cdot\left(\frac{C_{\mathrm{p}}}{\boldsymbol{C}_{\max }}\right)^{c}+w_{\mathrm{P}} \cdot\left(\frac{P_{\mathrm{p}}}{\boldsymbol{P}_{\max }}\right)^{c}+w_{\mathrm{PP}} \cdot\left(\frac{P P_{\mathrm{p}}}{\boldsymbol{P P}_{\max }}\right)^{c}+w_{\mathrm{V}} \cdot\left(\frac{V_{\mathrm{p}}}{V_{\max }}\right)^{c}+w_{\alpha} \cdot\left(\frac{\alpha_{\mathrm{p}}}{\boldsymbol{\alpha}_{\max }}\right)^{C}
\end{aligned}
$$

If $\left(M C F_{i}>1\right) \Rightarrow \mathrm{c}=2$

If $\left(M C F_{i}=1\right) \Rightarrow c=1$

If $\left(M C F_{i}<1\right)=>c=1 / 2$

$T_{\text {bulk }}$ expected bulk temperature in application

$T_{\max }$ maximum allowed temperature

$\sigma_{\mathrm{p}} \quad$ expected comparative stress level in application

$\sigma_{\text {max }}$ maximum allowed stress level

$Q_{\mathrm{p}} \quad$ requested product quality grade*

$Q_{\mathrm{AM}} \quad$ quality grade of the selected AM processing

Is $O_{\text {min }}$ requested isotropy level (1-10; for isotropic material Iso $=10$ )

$I s o_{\mathrm{AM}}$ isotropy level of the selected material
$C_{\mathrm{p}} \quad$ product total cost

$C_{\text {max }}$ maximum (acceptable) product total cost

$P_{\mathrm{p}} \quad$ product processing time

$P_{\max }$ maximum product processing time

$P P_{\mathrm{p}} \quad$ product pre-/post-processing time

$P P_{\max }$ maximum pre-/post-processing time

$V_{\mathrm{p}} \quad$ product volume

$V_{\max }$ maximum product volume

$\alpha_{p} \quad$ coefficient of material thermal expansion

$\alpha_{\max }$ maximum acceptable coefficient of material thermal expansion

$w_{\mathrm{i}} \quad$ weight or importance of a particular criterion $\left(0<w_{i}<1\right)$; default value $w_{i}=1$

\section{Table 1. Relations between quality grades and permissible geometric deviation for parts per} $100 \mathrm{~mm}$. Quality grades are proposed on the base of ISO 1328 standard for gears

$\begin{array}{llllllllllll}\text { Quality grade } & \text { Q7 } & \text { Q8 } & \text { Q9 } & \text { Q10 } & \text { Q11 } & \text { Q12 } & \text { Q13 } & \text { Q14 } & \text { Q15 } & \text { Q16 } \\ \begin{array}{l}\text { Permissible } \\ \text { deviations }[\mu \mathrm{m}]\end{array} & 18 & 25 & 36 & 51 & 72 & 102 & 144 & 204 & 288 & 408\end{array}$

The multi-criteria AM function contains the selection of technical and economic criteria. However, it is not limited to presented criteria only. In some applications shear stress resistance or module of elasticity is more important. Other applications may require resistance to dynamic loads or are sensitive to the coefficient of expansion due to moisture or temperature. Such specific criteria need to be checked manually or they need to be first integrated into the model. Product processing time $\left(P_{p}\right)$ is an important parameter to estimate AM production capacity. Maximum product processing time $\left(P_{\max }\right)$ can be calculated from AM machining capacity and requested product quantity in a specific time frame.

Most of the criteria need to be minimized. For example, comparative stress level must be below the maximal allowed level for the selected material and AM processing. Maximal allowed value is put in the denominator. If the criterion has an inverted scale such as quality level, then minimal request is put into numerator. The quality level of the selecting material and AM processing technology is written into denominator.

\subsection{Cost calculation model and case study}

In this case study, a cost calculation for the housing of a Raspberry Pi is performed. A design for AM assessment based on the design rules presented in section 4.2 , has approved the design. It is a technically undemanding product. We would like to use the machine that is already in-house. The input data is specified below.

Table 2. Input data for cost calculation for a specific AM processing

$\begin{array}{cll}\text { Symbol } & \text { Characteristic } & \text { Value } \\ V_{p} & \text { Volume of the part: } & 64 \mathrm{~cm}^{3} \\ \mathrm{M} & \text { Material: } & \mathrm{ABS} \\ T_{b u l k} & \text { Maximum bulk temperature in application } & 60^{\circ} \mathrm{C} \\ \sigma_{p} & \text { Material strength (the weakest direction) } & >8 \mathrm{MPa} \\ Q_{p} & \text { Requested product quality: } & \mathrm{Q} 13 \\ \mathrm{~N} & \text { Quantity: } & 20 \text { parts } \\ I s o_{A M} & \text { Requested minimal isotropy level for the product } & 5 \\ t_{1,2} & \text { Machine setting, Pre- and Post-processing time per part } & 0.3 \mathrm{~h} \\ C_{o p} / \mathrm{h} & \text { Operator cost } & € 30\end{array}$


Cost estimation and multi-criteria AM function is calculated on the base of the data in AM processing database for material ABS and AM processing FDM (extrusion) (Eq. (2)).

Material cost / part: $C_{M P}=V_{p} \cdot C_{M} \cdot \delta_{M}=0.064 \mathrm{dm}^{3} \cdot 30 € / \mathrm{kg} \cdot 1.04 \mathrm{~kg} / \mathrm{dm}^{3}=2,20 €$

Processing cost / part: $C_{P P}=V_{p} \cdot C_{P} \cdot C_{T}=0.064 \mathrm{dm}^{3} \cdot 0,625 € / \mathrm{h} \cdot 22 \mathrm{~h}=0.88 €$

Setting, pre-/post-processing costs / part: $C_{12}=t_{12} \cdot C_{o p}=0.3 \mathrm{~h} \cdot 30 € / \mathrm{h}=9 €$

Total costs for AM /part: $C_{\text {total }}=C_{M P}+C_{P P}+C_{12}=12.08 € /$ part

$$
\begin{aligned}
& \left.M C F=\left(\frac{T_{\text {bulk }}}{T_{\max }}\right)^{C}+\left(\frac{\sigma_{\mathrm{p}}}{\sigma_{\max }}\right)^{c}+\left(\frac{I s o_{\min }}{I_{\text {Iso }}}\right)^{c}+\left(\frac{\boldsymbol{Q}_{\mathrm{AM}}}{Q_{P}}\right)^{c}+\left(\frac{C_{p}}{C_{\max }}\right)^{c}+\left(\frac{P_{p}}{P_{\max }}\right)^{C 2}\right) \\
& \left.M C F=\left(\frac{60}{60}\right)^{1 / 2}+\left(\frac{8}{15}\right)^{1 / 2}+\left(\frac{5}{5}\right)^{1 / 2}+\left(\frac{\mathbf{1 4}}{13}\right)^{2}+\left(\frac{12.08}{9}\right)^{2}+\left(\frac{1.4}{2}\right)^{1 / 2}\right)=6.21
\end{aligned}
$$

The role of the multi-criteria AM function is to provide a holistic overview of how different criteria fulfil the initial design requests. The product designer can see which criteria are not fulfilled and change the product design accordingly. Another option is to change AM process; for example, with more advanced AM technology the technical characteristics are improved, and in this way fulfils product requirements. The presented example of multi-criteria AM function does not contain all possible criteria; it is a decision of the product designer.

\subsection{AM process selection}

The design engineer has an option to select optimal AM process with multi-criteria AM function (MCF). MCF is calculated for different materials and AM machines. Example contains PA and selective laser sintering (SLS).

Table 3. Material and processing data for cost calculation PA material and SLS

$\begin{array}{cll}\text { Symbol } & \text { Characteristic } & \text { Value } \\ \mathbf{M} & \text { Material } & \text { PA } \\ \mathbf{A M} & \text { AM Processing } & \text { SLS } \\ T_{\max } & \text { Maximum allowed temperature for the selected material } & 90^{\circ} \mathrm{C} \\ \sigma_{\max } & \text { Maximum allowed stress for the material } & 48 \mathrm{MPa} \\ \delta_{M} & \text { Specific weight of the material } & 0.93 \mathrm{~kg} / \mathrm{dm}^{3} \\ Q_{A M} & \text { Quality grade of selected AM processing } & 12 \\ I s o_{A M} & \text { Isotropy level of the selected material and AM processing } & 7 \\ C_{p} & \text { AM Processing cost per 1 hour* } & € 15.0 \\ C_{M} & \text { Material cost per 1 kg } & € 90.0 \\ C_{T} & \text { Processing time per 1 } \mathrm{dm}^{3} & 6 \mathrm{~h}\end{array}$

*Processing cost is based on AM machine value and depreciation rate.

Cost estimation and multi-criteria AM function was calculated on the base of the data in AM processing database for material PA and AM processing SLS (Eq. (3)).

Material cost: $C_{M P}=V_{p} \cdot C_{M} \cdot \delta_{M}=0.064 \mathrm{dm}^{3} \cdot 90 € / \mathrm{kg} \cdot 0.93 \mathrm{~kg} / \mathrm{dm}^{3}=6,96 €$

Processing cost: $C_{P P}=V_{p} \cdot C_{P} \cdot C_{T}=0.064 \mathrm{dm}^{3} \cdot 15 € / \mathrm{h} \cdot 6 \mathrm{~h}=5.76 €$

Setting, pre-/post processing costs/part: $C_{12}=t_{12} \cdot C_{o p}=0.2 \mathrm{~h} \cdot 30 € / \mathrm{h}=6 €$

Total costs for AM part: $C_{\text {total }}=C_{M P}+C_{P P}+C_{12}=18.72 € /$ part

$\left.M C F=\left(\frac{T_{\text {bulk }}}{T_{\max }}\right)^{C}+\left(\frac{\sigma_{\mathrm{p}}}{\sigma_{\max }}\right)^{C}+\left(\frac{I s_{\min }}{I s o_{\mathrm{AM}}}\right)^{C}+\left(\frac{Q_{\mathrm{AM}}}{Q_{P}}\right)^{C}+\left(\frac{C_{p}}{C_{\max }}\right)^{C}+\left(\frac{P_{p}}{P_{\max }}\right)^{C}\right)$
$\left.M C F=\left(\frac{60}{90}\right)^{1 / 2}+\left(\frac{8}{48}\right)^{1 / 2}+\left(\frac{5}{7}\right)^{1 / 2}+\left(\frac{\mathbf{1 2}}{13}\right)^{1 / 2}+\left(\frac{18.72}{\mathbf{9}}\right)^{2}+\left(\frac{0.38}{2}\right)^{1 / 2}\right)=7.38$

\section{DIscussion}

The comparison between two AM processes has shown that FDM meets the technical criteria. The quality grade is one level below the requested one, but it can be treated as still acceptable. The total cost of the part produced by SLS is significantly more expensive, $€ 6.64$. According to the much higher 
processing cost of using SLS machine an even a higher difference would be expected; however, higher productivity of the SLS machine at the end reduces the total cost difference.

Value of the MCF reflects the technical and economical characteristics of the printed part. If we compare a larger number of AM processes, we compare only the total value of MCF. A closer look at the particular criterion reveals what the potentials or weaknesses of the part design manufactured with a specific AM technology are. The MCF translates the assumption into numbers and enables taking decisions on the base of data.

If several hundred parts are needed, injection moulding must be checked as an alternative for AM manufacturing. Injection moulding tooling costs represent the main investment and cost. In the simplified calculation, the mould cost (ca. $€ 10000$ for a one cavity tool with manual handling) needs to be split between the number of parts. Polymer materials are in average 10 to 20 times cheaper than the materials for AM processing (Franchetti, and Kress, 2017). However, product developer needs to be aware that each additional modification of moulding tool is expensive. On the other side AM processing do not require any initial investment.

\subsection{Limitations of conducted research}

Results and decisions depend on accuracy of material data characteristics processed on a specific AM machine. Reliable and comparable material data and AM processing cost are crucial for selection. It is important to compare what is comparable. The material technical characteristics must, for instance, be measured according to the same standard, only in such case the materials and AM processing become comparable. The speed and cost of AM processing must be specified on the base of the same method, such as $50 \%$ of working area is utilized, layer thickens is $0.1 \mathrm{~mm}$. There are significant differences between AM machines and process parameters, even the same processing principle is used.

Optimization procedure and cost reduction is based on precise technical characteristics of materials and AM processing parameters. Materials and technologies are evolving very rapidly, therefore it is difficult to collect precise information. Technical characteristics of AM products depend on material, AM processing principle, type of AM machine, and even on processing parameters. Therefore, the multi-criteria function is never perfect, it is an estimation with some error. The proposed concept must be supported with permanently collecting of new materials' characteristics and AM processing data. The proposed model was applied to several products, especially in the context of a master thesis. The response was in all cases positive, the students commented that a systematic approach was helpful to raise awareness on all aspects. However, the current database of materials and AM processes is limited and there is no advanced software application with a user-friendly interface.

The multi-criteria function (MCF) can be calculated precisely only if several product design and operational details are known. In the conceptual phase, all geometrical details or all load cases are not known yet, therefore calculation is based on engineer assumptions. Nevertheless, even the value of MCF is only an approximation, the product designer get an valuable feedback and tool for comparison between different product designs and AM technologies. The MCF is a method that increases awareness on several criteria, but it needs a design engineer in the decision loop.

\section{CONCLUSIONS}

The main contribution of this paper is the multi-criteria AM function. It enables concurrent consideration of different technical and economical criteria. The AM function helps to compare how selected AM processing and product design influence the product cost already in the conceptual phase of design. The holistic overview of different options enables product optimization.

An open on-going activity is collecting reliable AM material data processed on different AM machines. A working model includes an institution which is verifying material data - predefined printed samples with technical measurements. Collected material data should be available on the Web and offer cost assessment together with contacts to AM processing providers. In the case a company has its own AM machine, the machine specification can be inserted to be considered alone or together with other providers.

The presented model is in the process of implementation as Web based application. In the next step the application will be tested by industrial partners and upgraded on the base of feedback. The application will bring the latest information on material and AM technology into conceptual phase of the product development process and enable the product designers take the right decision. 


\section{ACKNOWLEDGMENTS}

The research was conducted in the frame of Inex-adAM project - Increasing Excellence on Advanced Additive Manufacturing. The project was funded from European Union's Horizon 2020 research and innovation programme under grant agreement No. 810708 .

\section{REFERENCES}

Armillotta, A. (2008), "Selection of layered manufacturing techniques by an adaptive AHP decision model", Robotics and Computer-Integrated Manufacturing, Vol. 24, No. 3, pp. 450-461.

Atzeni, E., Salmi, A. (2012), "Economics of additive manufacturing for end-useable metal parts", International Journal of Advanced Manufacturing Technologies, Vol. 62, pp. 1147-1155.

Baumers, M., Beltrametti, L., Gasparre, A. and Hague, R. (2017), "Informing Additive Manufacturing technology adoption: total cost and the impact of capacity utilisation", International Journal of Production Research, Vol. 55, No. 23, pp. 6957-6970.

Becker, R., Grzesiak, A., \& Henning, A. (2005), "Rethink assembly design", Assembly Automation, Vol. 25, No. 4, pp. 262-266.

Byun, H. S., Lee, K. H. (2005). "A decision support system for the selection of a rapid prototyping process using the modified TOPSIS method", International Journal of Advanced Manufacturing Technology, Vol. 26, No. $11-12$, pp. $1338-1347$.

Diegel, O., Nordin, A., Motte, D. (2020), A Practical Guide to Design for Additive Manufacturing, Springer.

Douglas, T., (2016), "Costs, benefits, and adoption of additive manufacturing: a supply chain perspective", International Journal of Advanced Manufacturing Technologies, Vol. 85, pp. 1857-1876.

Ehrlenspiel, K., Kiewert, A., Lindemann, U., Hundal, M.S. (2007), Cost-Efficient Design, Springer.

Franchetti, M., and Kress, C. (2017), "An economic analysis comparing the cost feasibility of replacing injection molding processes with emerging additive manufacturing techniques", International Journal of Advanced Manufacturing Technology, Vol. 88, pp. 2573-2579.

Hopkinson, N. (2006), "Production Economics of Rapid Manufacture. An Industrial Revolution for the Digital Age", In: Hopkinson et al. (Eds), Rapid Manufacturing: An Industrial Revolution for the Digital Age, pp. 147-157, Wiley.

Inex-adAM (2019), "Advanced additive manufacturing handbook", project report: Increasing Excellence on Advanced Additive Manufacturing.

ISO 1328-1:2013, Cylindrical gears - ISO system of flank tolerance classification — Part 1: Definitions and allowable values of deviations relevant to flanks of gear teeth.

Kampker, A., Triebs, J., Alves, B. (Ford), Kawollek, S., and Ayvaz, P. (2018), "Potential analysis of additive manufacturing technologies for fabrication of polymer tools for injection moulding - A comparative study", 2018 IEEE International Conference on Advanced Manufacturing (ICAM), Yunlin, Taiwan.

Niaki, M.K., Nonino, F., Palombi, G., Torabi, S.A. (2019), "Economic sustainability of additive manufacturing: Contextual factors driving its performance in rapid prototyping", Journal of Manufacturing Technology Management, Vol. 30, No. 2, pp. 353-365.

Sculpteo (2015), "3D Printing/traditional manufacturing: guide to cost efficiency”. Villejuif, France.

Stjepandic, J., Wognum, N., Verhagen, W.J.C. (2015), Concurrent Engineering in the 21 st Century, Fundations, Developments and Challenges, Springer.

Tagliaferri, V., Trovalusci, F., Guarino, S., and Venettacci, S., (2019), "Environmental and Economic Analysis of FDM, SLS and MJF Additive Manufacturing Technologies", Materials, Vol. 12, No. 14, id. 4161.

Tavčar, J., Černe, B., Duhovnik, J., and Zorko, D. (2021), A Multi-criteria Function for Polymer Gear Design Optimization, Journal of Computational Design and Engineering, qwaa097.

Yosofi, M., Kerbrat, O., Mognol, P. (2018), "Framework to combine technical, economic and environmental points of view of additive manufacturing processes", 25th CIRP Life Cycle Engineering (LCE) Conference, 2018, Copenhagen, Denmark.

Yang, S., \& Zhao, Y. (2015), "Additive manufacturing-enabled design theory and methodology: A critical review", International Journal of Advanced Manufacturing Technology, 80, pp. 327-342.

Vasco, J., Barreiros, F.M., Nabais, A., Reis, N. (2019), “Additive manufacturing applied to injection moulding: technical and economic impact”, Rapid Prototyping Journal, Vol. 25, No., pp. 1241-1249. 